\title{
Danielle Mihram
}

\section{The University of Southern California Voltaire Letters}

\section{A polymathic multimodal digital project}

n spring 2015 one catalog record in the

University of Southern California (USC) Special Collections came to my attention: Voltaire correspondence, 1741-1777. The correspondence consists of 30 original autograph letters and four poems authored by Voltaire (François-Marie Arouet, 1694- by Christian R. Dick (university librarian at that time), and they were originally housed in the Hoose Library of Philosophy. They were subsequently merged (exact date unknown) into our special collections. ${ }^{2}$

Throughout the 18th century, the exchange of letters was tantamount to an intellectual

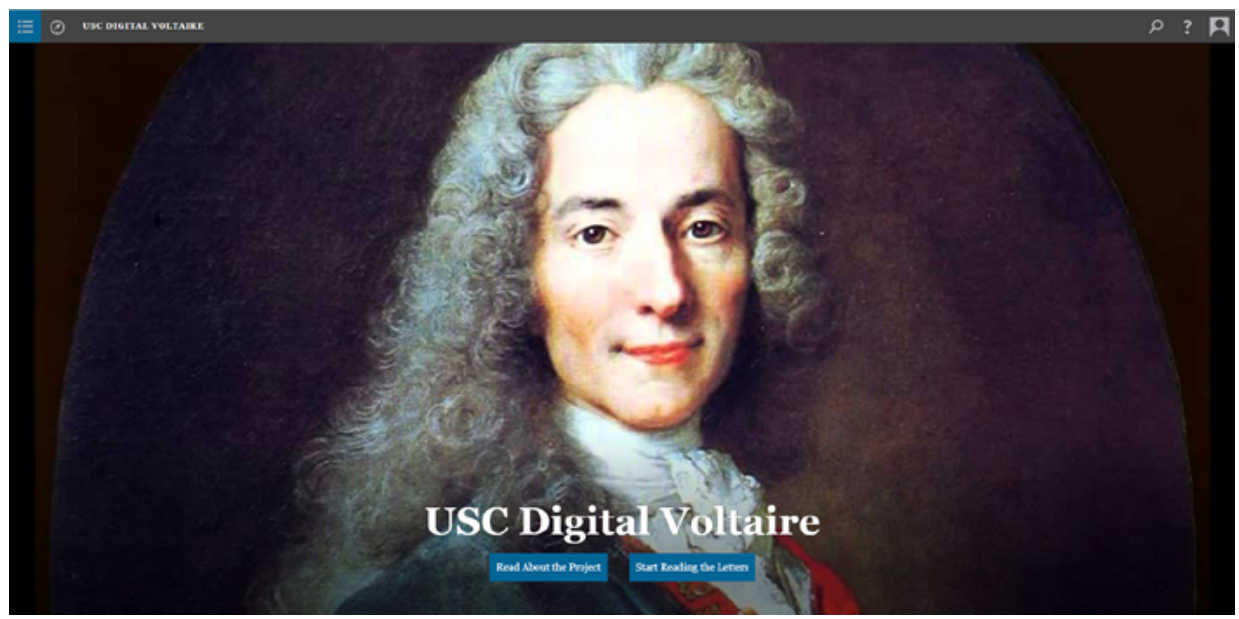

USC Digital Voltaire screenshot.

1778) and his circle, including leading figures of the Enlightenment such as Jean le Rond d'Alembert (1717-1783), Frederick II of Prussia (1712-1786), and Madame de Pompadour (1721-1764) - the acknowledged mistress of Louis XV (1710-1774).

These letters were acquired in 1945 (from a catalog published by the Cosmopolitan Science and Art Service Company) ${ }^{1}$ powerhouse at work. Their impact on the Enlightenment was electrifying. In the case of Voltaire, his voluminous correspondence

Danielle Mihram is university librarian at the University of Southern California's (USC) Libraries and a distinguished faculty fellow at the USC Center for Excellence in Teaching, email: dmihram@usc.edu

C 2017 Danielle Mihram 
is a multifaceted private expression of self, through epistolary exchanges, and it offers a multilayered perspective of one of the leading minds that defined his century.

In the case of the USC collection of Voltaire's letters, it occurred to me that we had a unique opportunity to engage in our current and newly emerging modes of scholarly communication by enriching these letters via a digital multimodal critical edition. Essentially, the use of a polymathic approach would give us the opportunity to explore the multiple interdisciplinary dimensions of these letters by including the compilation of metadata; high-resolution images of our original manuscripts; an examination of the letters as "artifacts" (e.g., quality of paper and handwriting analysis); paleographic elements

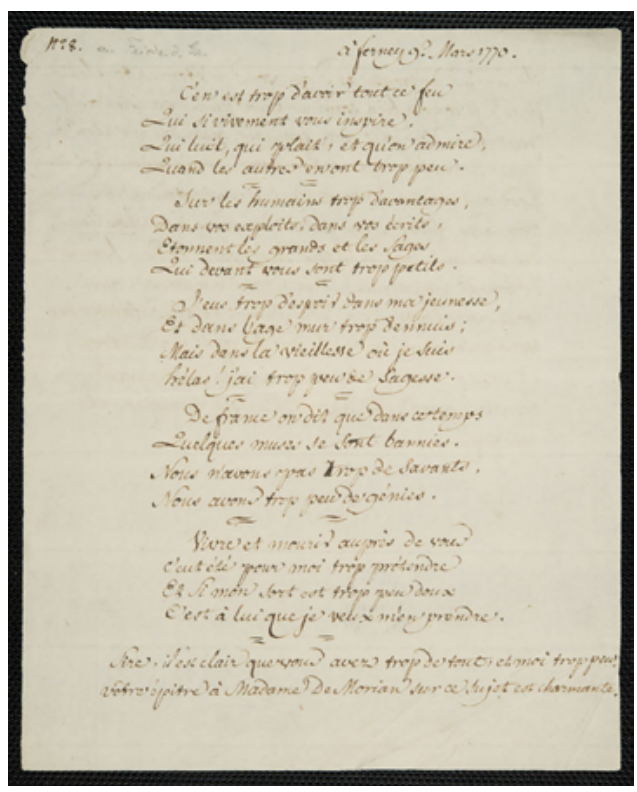

One of the Voltaire letters. by Voltaire himself, and published online in Oxford University's Electronic Enlightenment, ${ }^{5}$ amounts to 16,136 .

Voltaire himself acknowledged the overwhelming volume of this correspondence: On January 15, 1761, in his letter to Mme Du Deffand, he (then aged 67) stated that he was "crushed by a correspondence stretching from Pondicherry ${ }^{6}$ to Rome."

Though somewhat minuscule in scope, when compared to the overall enormity of the Voltaire correspondence, the letters in our collection include multiple topics: both religious freedom and the freedom of expression in France, the Catholic Church, the War of Austrian Succession, the Seven Years War, Voltaire's own remarks on many of his works, his commentary (at times quite biting) on his contemporaries' writings, the theatritranscription of each letter); each letter's translation in English; and the writing of a multitude of detailed notes relating to the people, events, and places that are noted within the Voltaire letters.

\section{The USC Voltaire Letters: A matter of scope}

In the 1960s, Voltaire's entire published epistolary corpus comprised more than 20,000 letters. ${ }^{3}$ New manuscripts continue to come to light, adding to the growing corpus. In 2009 , the number of letters amounted to 21,222 (with more than 15,000 by Voltaire himself) spread over 70 years, and including 1,800 correspondents. ${ }^{4}$ At last count (July 2017), the number of letters authored cal life of the period, his judicial campaigns in favor of the victims of intolerance; and his own health.

The letters do provide an opportunity for the researcher to analyze very closely each letter with respect to its date, its relationship between author and addressee, and the many forms of discourse within the subject matter in the letters. It has become, for us, the basis for an experimental librarian-led goal to create a scholarly critical edition that could form a basis, as well as a set of best practices, for curated online projects on Voltaire's epistolary manuscripts.

The existence of our manuscript collection was known by Theodore Besterman digital humanities project, with the initial 
(editor of Voltaire's correspondence) who, apparently, had photographic reproductions of 29 of our manuscripts. In his various publications of Voltaire's correspondence, including the monographic series Complete Works of Voltaire, ${ }^{7}$ he identifies most of the letters in our collection as manuscripts in the "James Harmon Hoose Library of Philosophy, USC Libraries, University of Southern California, Los Angeles, California [state], United States (SHELFMARK: MS fF840, v935d).”

\section{The USC Voltaire Letters Project}

Most digital humanities projects are initiated on a small scale, involving a limited number of researchers and very modest funding. For the initial stage of our project, I assembled a team of colleagues and arranged for the digitization of all of the letters for their inclusion in our Digital Library. ${ }^{8}$ We also successfully competed for one of Dean Catherine Quinlan's Challenge Grants. This small one-year grant (which began in May 2016) has provided us with the necessary "start-up financial support" for the work to be undertaken by students who were assigned specific tasks.

At the outset, we had to agree on several issues so as to contextualize the letters within the digital humanities, including framing the letters within a particular scholarly and methodological structure, deciding on a digital platform, selecting an editorial framework (as well as editorial parameters), positioning the letters for potential use within emergent humanities research and curriculum models, and developing a roadmap for funding beyond our initial grant.

In the context of our envisioning a critical edition of the letters, we needed to analyze each letter (or poem) very carefully, and, in addition, check the information for each letter provided in the Electronic Enlightenment. With regard to the transcriptions, we needed (and I have created) a guide to the transcription conventions of French 18th-century manuscripts based on the suggestions made by two leading paleographers: Gabriel Audisio 9 and, in particular, Béatrice Beaucourt-Vicidomini. ${ }^{10}$

\section{Our publishing platform}

We selected Scalar ${ }^{11}$ as our publishing platform, and our project's publication, titled USC Digital Voltaire. ${ }^{12}$

Scalar, a USC-based open source online publishing tool was developed by the Alliance for Networking Visual Culture for the electronic journal Vectors..$^{13}$ Multimedia-rich, it supports embedded video and audio along with functionalities for visualizations, annotations, extensive media tagging, and direct importations of content from partnership with several archives, such as the Hemispheric Institute's Digital Video Library, ${ }^{14}$ the Internet Archive,${ }^{15}$ and Critical Commons. ${ }^{16}$

Our project includes nine library employees (library faculty and staff at the USC Libraries), whose specific skill sets and expertise include metadata creation, web design, Scalar "know-how," and, including myself (as principal investigator), librarians with specific knowledge-based specialization. ${ }^{17}$ The project also includes two volunteers (one a former student and the other a former library intern), an 18th-century consultant (a faculty colleague in the French and Italian Department), as well as four student assistants. As the project continues to elicit interest, a larger number of faculty and students will have the opportunity to contribute to its development. We are targeting any scholars and advanced researchers worldwide who use primary materials in our collections relating to the United States, Europe, and beyond.

Our six goals (delineated in detail in our "Scalar book") include the following: highlighting our special collections' primary and secondary sources within a specific area; serving as one of the very first collaborative interdisciplinary digital humanities initiatives entirely created and authored by librarians; reaching scholars and students beyond the traditional disciplines generally associated with Voltaire and the Enlightenment; developing strategic alliances by linking scholars 
and students from different fields of the humanities with those in the social sciences; and providing a model of interdisciplinary collaboration that affords multiple levels of discovery, thus opening new research perspectives on major Enlightenment events and persons.

Currently, this project stands at its initial stage of its implementation: Creating a polymathic and multimodal critical edition of the Voltaire letters in our collection. The second phase of the project (with external funding) will allow for (editorially controlled) usergenerated content by enabling users to "mark up" texts, maps, illustrations, and born-digital materials, so as to further enrich the content.

\section{The USC Voltaire Letters Project and the digital humanities}

Our project can be situated at the intersection of several genres in digital scholarship, digital publishing, and the digital humanities. In some ways, it is part of a line of projects typically referred to (in the digital humanities' environment) as digital archives (in library parlance: digital collections).

In particular, our project fits within the overall aim of those digital archives/collections that are constructed as thematic research collections (bringing together primary sources and related material to support explicitly research on a particular theme).

At the same time, our project seeks to describe, situate, and showcase a particular collection held and maintained by a particular institution, as, for example, the online scholarly catalogs of various museums created since the Getty-funded Online Scholarly Catalog Initiative toolkit, launched in 2009. ${ }^{18}$

\section{A work in progress}

This project is currently a work in progress as we continue editing all of the letters in our collection. Nonetheless, even at this stage of development, our project is eliciting attention. Recently, during his travels and presentations to various institutions, our Scalar specialist Curtis Fletcher has included brief overviews of our project. He also gave an overview of our project at the April 2017 meeting of the USC Libraries Board of Councilors. The Board's interest in (and support of) our project's goals suggests that other collections, currently located in our Special Collections' Department, may be considered as excellent candidates for such project-development.

Equally very important to us is our own students' enthusiasm in participating in the project. What cannot be overstated is their enthusiasm in participating in "real research." They are, on an ongoing basis, highly motivated because of their handling real paper (their words!) crafted in the 18thcentury and featuring watermarks, and they discovered the amazing (their word!) pace of handwriting with a quill pen (by identifying the differences in ink concentration on the line leading to necessary dipping of the pen into the ink).

In the context of scholarly research, they are thrilled to read the thoughts and worries expressed in these letters by individuals, such the King of Prussia and the other leading figures with whom Voltaire communicated, and to find and then comprehend (with visible delight) the code words and pseudonyms used in order to evade the French King's censure. Reading history as it unfolds in "real time," yet centuries ago is, according to them, an unforgettable experience.

I cannot think of a better way to conclude this overview of our project than by sharing the response of one of the students who participated in our project.

To the question, Would you recommend the project to other students? Why? she responded as follows (echoing many other similar comments by our students):

Yes! This is, in practical terms, better than almost any class you can take. Here, you are surrounded by multiple experts, from different fields, and you have the opportunity to learn how challenging and rewarding research in the real world is, and what it 'looks 
like.' Plus, you have the option to work a lot when you have time, and slow down when exams start, or life hits. Although the deadlines are of course real and important, this is a long-term project and that just feels different than anything done in class. . . . Professors get so loaded down with their classes and publications that they can't provide students (or post-students) with the same quality of support. Helping this team has certainly helped me and for that I am forever grateful!

\section{Notes}

1. Cosmopolitan Science and Art Service Company, "Voltaire, Fr. M. Arouet de (1694-1778) A Fine Collection Original Letters by Voltaire and His Circle," New York, 1945, cat.17, entry no. 1706.

2. Voltaire, Voltaire correspondence, 1741-1777, Vault: Collection 6006 Box 1.

3. Theodore Besterman, "Twenty Thousand Voltaire Letters," in Editing EighteenthCentury Texts: Papers Given at the Editorial Conference, University of Toronto, October 1967, edited by D. I. B. Smith, 7-24 (Toronto: University of Toronto, 1968). See also the Voltaire Foundation's blog post by Martin Smith: "Les Euvres complètes de Voltaire, the first 25 years-the pioneers," July 2017, https://voltairefoundation. wordpress.com/.

4. Christiane Mervaud, "Voltaire's Correspondence," in The Cambridge Companion to Voltaire, edited by Nicholas Cronk, 153-166 (Cambridge; New York: Cambridge University Press 2009): 153-166.

5. Electronic Enlightenment_Letters and Lives Online (Voltaire Foundation: Oxford University, 2008- ), www.e-enlightenment. $\mathrm{com} /$.

6. Pondicherry was a French colonial settlement in India until 1954.

7. Complete Works of Voltaire, Institut et Musée Voltaire (Voltaire Foundation: 1968- ), www.voltaire.ox.ac.uk/www_vf/ ocv/ocv_index.ssi.
8. Voltaire correspondence, 1742 1777, http://digitallibrary.usc.edu/cdm /landingpage/collection/p15799coll47.

9. Gabriel Audisio, "Transcrire un Texte," La Revue Française de Généalogie, 208 (October-November 2013): 52-53. See also: Gabriel Audisio and Isabelle Rambaud, Lire le Français d'hier: Manuel de Paléographie Moderne XVe-XVIIIe siècle, Cinquième édition revue et augmentée. Paris: Armand Colin, 2016.

10. Béatrice Beaucourt-Vicidomini, Manuel de Paléographie Moderne, XVIeXVIIIe Siècles (Paris: Archives \& Culture, 2012): 44.

11. Scalar, http://scalar.usc.edu.

12. USC Digital Voltaire, accessible at http://scalar.usc.edu/works/voltaire/index.

13. Tara McPherson, "Introduction: Media Studies and Digital Humanities," Cinema Journal 48, No. 2 (Winter 2009): 119-123.

14. Hemispheric Institute's Digital Video Library, http://hemisphericinstitute. org/hemi/en/hidvl.

15. The Internet Archive, https:// archive.org.

16. Critical Commons, www. criticalcommons.org)

17. Their names are listed here, in alphabetical order, with parenthetical indication of expertise or of knowledge-base: Curtis Fletcher (Scalar), Karen Howell (Scholarly Technology), Mike Jones (Web Design), Rachel Mandell (Metadata), Danielle Mihram (French and Italian; Digital Humanities), Wayne Shoaf (Metadata), Ross Scimeca (Philosophy), Michaela Ullmann (Exile Studies), and Ruth Wallach (Art and Art History). Our two volunteers (for the long-term) are Sasha Pearce (USC undergraduate degree, History: 2016; now graduate studies at Middlebury College and the Sorbonne) and Karén TerSarkisian (History, library intern at USC: Spring 2016; now reference librarian at the City of Commerce Public Library).

18. Online Scholarly Catalog Initiative toolkit, www.getty.edu/foundation /initiatives/current/osci/. $\neq 2$ 